\title{
Peran Visual Merchandising dan Store Image terhadap Peningkatan Customers' Purchase Intention
}

\author{
Kartika Anggraeni Sudiono Putri ${ }^{1}$, Ikhsan Maksum ${ }^{2}$, Amelindha Vania ${ }^{3}$ \\ 1,2,3 Universitas Islam Negeri Maulana Malik Ibrahim Malang \\ Email Address: \\ kartikaanggraeni@uin-malang.ac.id; Ikhsan.maksum@uin-malang.ac.id: amelindhavania@uin- \\ malang.ac.id
}

\begin{abstract}
The purpose of this study is to examine the effect of visual merchandising to store image and purchase intention through the importance of visual merchandising factors such as front entrance product display, merchandising displays, store layout and organization, merchandising theme, signage/graphic, lighting and sound usage. This study also looked at the effects of store image on purchase intention. Ikea Alam Sutera Indonesia is used as a research object because in Ikea store, visual merchandising elements are designed in detail to create a unique shopping atmosphere for customers. The sample was 250 respondents drawn through non-probability sampling technique used purposive sampling with criteria of respondents had visited Ikea Alam Sutera. Data were analyzed using Structural Equation Modeling (SEM) with AMOS program version 24.0. The result shown that visual merchandising has positive influence on store image, whereby the greatest influence factors are lighting, merchandising theme and merchandising display. Nevertheless, visual merchandising did not have influence on purchase intention. Purchase intention known to be positively influenced by store image.
\end{abstract}

Keywords: visual merchandising, store image, purchase intention.

\begin{abstract}
Abstrak: Penelitian ini memiliki tujuan untuk mengetahui pengaruh positif visual merchandising terhadap store image dan purchase intention melalui front entrance product display, merchandising display, store layout and organization, merchandising theme, signage/graphic, lighting dan sound usage. Penelitian ini juga melihat pengaruh positif store image itu sendiri terhadap purchase intention. Ikea Alam Sutera Indonesia digunakan sebagai objek penelitian karena di dalam ritel Ikea, elemen visual merchandising dirancang secara mendetil untuk menciptakan suasana berbelanja yang unik bagi pelanggannya. Sampel yang digunakan berjumlah 250 responden yang diambil melalui teknik non probability sampling yaitu menggunakan purposivee sampling dengan kriteria responden pernah berkunjung ke Ikea Alam Sutera. Data yang diperoleh dianalisis menggunakan Structural Equation Modeling (SEM) dengan program AMOS versi 24.0. Dari hasil penelitian dikertahui bahwa visual merchandising memiliki pengaruh positif terhadap store image dengan 3 dimensi yang berpengaruh paling besar yaitu lighting, merchandising theme dan merchandising display. Namun visual merchandising tidak menunjukan hasil memiliki pengaruh terhadap purchase intention. Purchase intention dipengaruhi secara positif oleh store image.
\end{abstract}

Kata Kunci: visual merchandising, store image, purchase intention. 


\section{PENDAHULUAN}

Menurut proyeksi data Himpunan Industri Mebel dan Kerajinan Indonesia (Himki), pertumbuhan penjualan produk furnitur diprediksi tumbuh sebanyak 12 persen pada tahun 2020. Belanja furnitur menjadi sesuatu yang penting karena konsumen yang semakin paham akan desain dan perabot yang mereka inginkan untuk mengisi interior rumah mereka. Furnitur maupun perabot rumah tangga lainnya merupakan kategori produk yang pengaturan desainnya di toko ditampilkan secara kreatif sesuai dengan tema warna atau tren yang sedang digemari. Strategi tersebut digunakan untuk menarik perhatian pelanggan saat berbelanja.

Kompetisi di industri ritel furnitur yang sedang bertumbuh ini membuat peritel perlu memastikan bahwa produknya mampu menarik pelanggan dengan lebih efektif. Selain menggunakan alat komunikasi tradisional seperti iklan atau promosi penjualan lainnya, yang tidak kalah penting ialah bagaimana merancang suasana di dalam gerai/toko. Saat mendesain interior, berbagai komponen harus selaras untuk mendapatkan emosi yang menyenangkan, yang membuat pelanggan bukan hanya ingin kembali ke toko tetapi dapat menyebarkan citra toko yang baik kepada orang lain (Kleinova dkk, 2015). Hal ini didukung pula oleh pelanggan yang semakin mencari pengalaman multi-sensory di dalam toko.

Salah satu cara memperoleh suasana gerai untuk mampu menarik perhatian pelanggan ialah dengan merancang visual merchandising. Visual merchandising atau disingkat dengan VM, hadir sebagai nilai pembeda di antara pengaturan lingkungan ritel. Penggunaan berbagai elemen VM dapat mempengaruhi emosi dan perilaku pelanggan. (Gudonaviciene and Alijosiene, 2015; Kposa and Lick, 2020). (Mehta dan Chugan, 2014) juga membuktikan bahwa VM membantu untuk menghasut keinginan membeli pengunjung.

Salah satu ritel modern yang membaca peluang pasar furnitur di Indonesia ialah Ikea. Ikea merupakan super store asal Swedia yang telah beroperasi di kawasan Alam Sutera sejak tahun 2014. Gerai Ikea menawarkan produk furnitur dan peralatan rumah tangga hingga aksesoris pendukungnya. Ikea sangat diminati untuk dikunjungi karena memiliki banyak ruang pamer produk yang didesain secara inspiratif dan tematik, dimana pengunjung akan merasa seperti mengunjungi ruangan di dalam rumah modern. Pengalaman berbelanja yang dihadirkan oleh Ikea melalui ruang pamer yang realistik menjadi nilai tambah karena mampu menarik perhatian pengunjung dan membantu merasakan pengalaman ruang serta menggunakan produk sebelum melakukan pembelian.

Ikea Alam Sutera memberikan perilaku khusus pada penampilan gerainya melalui detail pada elemen-elemen visual merchandising. Beberapa dimensi atau elemen VM yang digunakan di Ikea Alam Sutera yaitu produk yang disorot pada bagian area masuk toko (front entrance product display), tampilan produk yang unik (merchandising display), layout toko yang efektif (store layout \& organization), tema yang kreatif (merchandising theme), petunjuk atau grafis (signage/graphic) yang jelas, pencahayaan (lighting) yang nyaman dan penggunaan musik (sound usage). (Hosseini, 2014) menjelaskan bahwa suasana toko menjadi alat utama yang dapat digunakan peritel untuk meningkatkan perilaku pelanggan terutama terhadap keputusan pembelian di toko. Menciptakan suasana berbelanja melalui penataan produk dan tema yang menarik, tata letak dan informasi produk yang jelas serta pencahayaan dan lingkungan yang nyaman dapat memberi pengaruh yang kuat dalam membentuk citra toko yang positif. 
Persepsi pelanggan mengenai visual merchandising dapat membangkitkan minat pelanggan di dalam toko untuk mengeksplor produk, berinteraksi menggunakan produk, berkontribusi pada preferensi merek hingga mendorong niat pembelian (Park dkk, 2015). Pengaruh suasana toko pada saat berbelanja yang memberikan kenyamanan dan kesenangan menghabiskan waktu di dalam toko, berhubungan dengan keputusan untuk membeli dan tidak membeli (Turley dan Milliman, 2000; Seock dan Lee, 2013). Oleh karena itu penelitian ini bertujuan untuk menguji peran ketujuh elemen visual merchandising yang diterapkan di Ikea Alam Sutera dalam menciptakan store image yang positif di benak pelanggan dan pengaruhnya terhadap niat membeli pelanggan.

\section{KAJIAN TEORI}

Visual merchandising (VM) didefinisikan sebagai sebuah seni menampilkan produk melalui cara yang atraktif sehingga dapat menarik perhatian pelanggan dan meyakinkan mereka untuk membeli produk (Krishnakumar, 2014). VM memfasilitasi pembuatan platform untuk menampilkan produk (merchandise) secara inovatif dalam wujud 3 dimensi, sebagai strategi untuk menarik pelanggan dalam jangka waktu panjang. Beberapa elemen umum dari visual merchandising yaitu storefront, store layout, store interior dan interior display (Marketing Essentials, 2012).

Elemen-elemen VM harus dapat menangkap emosi dan persepsi dari pelanggan (Zolkifly dan Baharom, 2016). Hal ini disebabkan elemen VM yang efektif dipercaya dapat membangun dan menjaga citra fisik dan psikologis toko di pikiran pelanggan (Bell dan Ternus, 2012). Stimulasi yang diberikan kepada pelanggan dimulai dari area masuk toko hingga produk yang harus ditampilkan dengan cara yang menarik untuk memikat pelanggan. Berbagai elemen seperti tampilan display pada area masuk toko, tampilan produk, tata letak, tema, grafis, musik dan pencahayaan yang menciptakan persentasi visual, membutuhkan kreativitas, keahlian, inovasi dan perencanaan yang baik agar dapat memberikan keunggulan kompetitif dalam menciptakan citra toko secara menyeluruh (Krishnakumar, 2014).

Display produk yang ditampilkan pada area masuk toko adalah alat komunikasi visual yang akan menciptakan kesan pertama pada pelanggan (Mehta dan Chugan, 2012). Tampilan produk pada area masuk ini merupakan faktor yang dapat membuat pelanggan berhenti sejenak, mendekat, menyentuh atau mencoba produk sehingga pelanggan semakin tertarik untuk segera menjelajah toko (entrepreneur.com, 2015). Front entrance product display yang kreatif dapat menjadi faktor yang dapat mempengaruhi minat dan keinginan pembelian pelanggan (Bakarne, 2008; dalam Mehta dan Chugan, 2014).

Merchandising display dapat didefinisikan sebagai pengelompokan produk, pengaturan rak, alokasi ruang lantai dan dekorasi dinding (Banat dan Wandebori, 2012). Merchandising display menjadi stimuli untuk menarik konsumen dan memiliki pengaruh yang kuat pada niat pembelian serta persepsi konsumen terhadap produk (Hussain dan Ali, 2015).

Store layout and organization atau tata letak toko adalah perencanaan alokasi areaarea spesifik atau ruang untuk masing-masing produk serta area yang termasuk non-selling (Krishnakumar, 2014). Tata letak toko membentuk ruang perilaku dan kepadatan dalam toko (Borges, 2013). Tata letak toko merupakan salah satu atribut yang mempengaruhi 
kepuasan dan niat beli pelanggan (Watanabe dkk, 2019). Pembelian produk didukung oleh tata letak dan organisasi toko yang jelas sehingga pelanggan dengan mudah meraih produk tanpa ada halangan sehingga dapat mempengaruhi niat beli pelanggan.

(Seock dan Lee, 2013) berpendapat bahwa salah satu dimensi penting dalam visual merchandising pada ritel furnitur adalah koordinasi tema yang kreatif (merchandising theme). Tema yang baik dapat meningkatkan mood pelanggan di dalam toko, mempengaruhi imaginasi, membantu pelanggan mengetahui bagaimana atau dimana mereka akan menggunakan produk, memberi referensi/ide dari tampilan tren atau tema warna sehingga dapat mendorong pembelian (Madhavi dan Leelavati, 2013). Melalui tema warna yang diaplikasikan pada pengaturan produk, perasaan konsumen dapat dibangun dan hal ini dapat mempengaruhi perilaku konsumen (Banat dan Wandebori, 2012).

Signage/graphic bertindak sebagai "silent salesperson", berfungsi untuk membatasi area dari bermacam-macam golongan produk, mempublikasikan berberapa promosi produk dan mengindikasikan fasilitas/pelayanan yang disediakan oleh toko. Signage menyediakan informasi penting bagi pelanggan untuk dapat digunakan dalam membuat keputusan pembelian (Seock dan Lee, 2013; Rajendhiran dan Manimozhian, 2015).

Menurut (Pecotic et al., 2014), pencahayaan (lighting) yang buruk dapat dianggap sebagai pengalaman yang buruk bagi pelanggan. Sebaliknya rangsangan dan pencahayaan yang berpengaruh positif untuk menarik pelanggan, memacu pembelian, dan memfasilitasi penyempurnaan dari penjualan (Kouchekian dan Gharibpoor, 2012). Secara umum toko yang terang dengan pencahayaan yang secara cerdik dipadukan di dalam interior membawa kenyamanan yang lebih tinggi bagi para pelanggan, dengan demikian lebih banyak penjualan yang terjadi (Madhavi dan Leelavati, 2013).

Musik adalah salah satu usaha penggunaan suara/bunyi yang menyenangkan dan dapat mempengaruhi keputusan sadar atau tidak sadar konsumen (Banat dan Wandebori, 2012). Sound atau musik yang menyenangkan berasosiasi dengan konsumsi waktu konsumen yang lebih lama di toko (Holbrook dan Anand, 1990; Smith dan Ross, 1966), sehingga secara signifikan dapat mempengaruhi niat beli pelanggan (Hussain dan Ali, 2015).

Pengalaman berbelanja di lingkungan toko yang menyenangkan yang tercipta dari presentasi display produk yang menarik, eksekusi tema dan tampilan yang kreatif, papan petunjuk dan tata letak yang jelas, pencahayaan yang ciamik serta sound atau musik yang nyaman berkontribusi sangat besar terhadap keseluruhan citra toko (Seock dan Lee, 2013). Image tertentu dan pengalaman positif terhadap toko dapat menimbulkan keinginan untuk membeli lebih di kemudian hari dan keinginan untuk merekomendasikan toko kepada orang lain serta mentransfer good word of mouth.

\section{METODE}

Penelitian ini mengacu pada beberapa penelitian mengenai pengaruh dimensi visual merchandising pada pengaturan di ritel furnitur. Penulis menggunakan model yang serupa dengan model dari penelitian terdahulu seperti yang ditulis oleh (Kouchekian dan Gharibpoor, 2012), (Seock dan Lee, 2013), (Mehta dan Chugan, 2014) dengan beberapa penyesuaian sesuai kondisi eksisting objek penelitian. Penulis membedakan objek 
penelitian yang diteliti, yaitu Ikea yang berlokasi di Alam Sutera, Tangerang, Indonesia. Berikut adalah model penelitian yang digunakan pada penelitian ini:

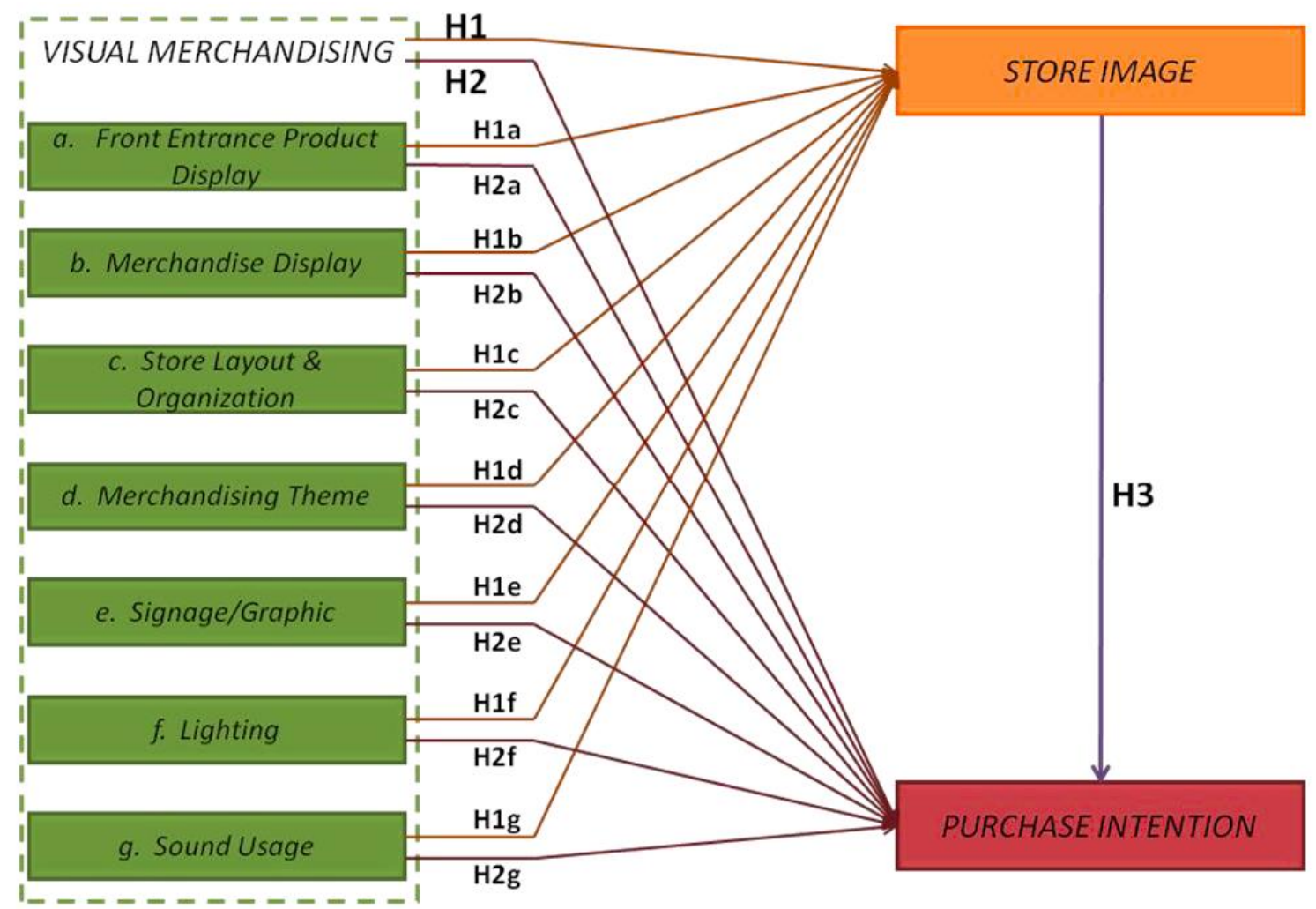

Gambar 1. Hubungan Visual Merchandising dan Store Image terhadap Customers' Purchase Intention Sumber: Diolah dari Kouchekian \& Gharibpoor, 2012; Seock \& Lee, 2013; Mehta \& Chugan, 2014

Model penelitan tersebut akan menguji tiga hipotesis utama sebagai berikut:

$\mathrm{H}_{1}$ : Visual merchandising berpengaruh positif terhadap store image.

$\mathrm{H}_{1 \mathrm{a}}$ : Front entrance product display berpengaruh positif terhadap store image.

$\mathrm{H}_{1 \mathrm{~b}}$ : Merchandising display berpengaruh positif terhadap store image.

$\mathrm{H}_{1 \mathrm{c}}$ : Store layout \& organization berpengaruh positif terhadap store image.

$\mathrm{H}_{1 \mathrm{~d}}$ : Merchandising theme berpengaruh positif terhadap store image.

$\mathrm{H}_{1 \mathrm{e}}$ : Signage/graphic berpengaruh positif terhadap store image.

$\mathrm{H}_{1 \mathrm{f}}$ : Lighting berpengaruh positif terhadap store image.

$\mathrm{H}_{1 \mathrm{~g}}$ : Sound usage berpengaruh positif terhadap store image.

$\mathrm{H}_{2}$ : Visual merchandising berpengaruh positif terhadap purchase intention.

$\mathrm{H}_{2 \mathrm{a}}$ : Front entrance product display berpengaruh positif terhadap purchase intention.

$\mathrm{H}_{2 \mathrm{~b}}$ : Merchandising display berpengaruh positif terhadap purchase intention.

$\mathrm{H}_{2 \mathrm{c}}$ : Store layout \& organization berpengaruh positif terhadap purchase intention.

$\mathrm{H}_{2 \mathrm{~d}}$ : Merchandising theme berpengaruh positif terhadap purchase intention.

$\mathrm{H}_{2 \mathrm{e}}$ : Signage/graphic berpengaruh positif terhadap purchase intention.

$\mathrm{H}_{2 \mathrm{f}}$ : Lighting berpengaruh positif terhadap purchase intention. 
$\mathrm{H}_{2 \mathrm{~g}}$ : Sound usage berpengaruh positif terhadap purchase intention.

\section{H3: Store image berpengaruh positif terhadap purchase intention.}

Indikator pada kuisioner penelitian ini berjumlah 45 indikator, sehingga minimal sampel yang harus dikumpulkan menurut Malholtra (2010) minimal berjumlah 225 responden. Dalam penelitian ini penulis mengambil sampel sebanyak 250 responden. Metode pengambilan sampel yang digunakan adalah purposive sampling yaitu teknik pengambilan sampel dengan menentukan kriteria tertentu (Sugiyono, 2008) dimana kriteria untuk penelitian ini adalah responden pernah mengunjungi Ikea Alam Sutera. Penelitian ini akan menggunakan dua software analisis statistik yaitu SPSS dan AMOS versi 24.0. Analisis data menggunakan metode Structural Equation Modeling (SEM) untuk memeriksa struktur keterkaitan antar variabel yang dinyatakan dalam serangkaian persamaan struktural dan menentukan model penelitian valid (Malholtra, 2010).

\section{HASIL}

Analisis deskriptif pada karakteristik profil responden pada Tabel 1 menunjukan bahwa mayoritas pengunjung ialah yang berdomisili di Jabodetabek dengan rentang usia 21 sampai 30 tahun, memiliki pendidikan terakhir S1/sederajat, berprofesi sebagai karyawan dengan pengeluaran rutin perbulan di luar biaya cicilan rumah/mobil sebesar 2.000.001 hingga 4.000.000. Sementara khusus untuk pengeluaran furnitur atau perabot rumah tangga, mayoritas responden mengeluarkan biaya $\leq 1$ juta perbulan. Hasil penelitian ini juga mengidentifikasi bahwa pengunjung Ikea Alam Sutera rata-rata memiliki tujuan untuk membeli furnitur/perabot dan mencari inspirasi desain. Lamanya durasi waktu yang dihabiskan ketika berbelanja di Ikea Alam Sutera kurang lebih 1-2 jam dan 80\% responden menyatakan bahwa mereka melakukan pembelian.

Tabel 1. Profil responden

\begin{tabular}{llrr}
\hline Item & Karakteristik & Frekuensi & \multicolumn{1}{c}{$\%$} \\
\hline Jenis kelamin & Laki-laki & 109 & 44.0 \\
& Perempuan & 141 & 56.0 \\
Usia & $\leq 20$ tahun & 11 & 4.0 \\
& $21-30$ tahun & 194 & 78.0 \\
& $31-40$ tahun & 41 & 16.0 \\
& $>40$ tahun & 4 & 2.0 \\
Domisili & Jakarta & 151 & 61.0 \\
& Bogor & 13 & 5.0 \\
& Depok & 15 & 6.0 \\
& Tangerang & 48 & 19.0 \\
& Bekasi & 15 & 6.0 \\
& Lainnya & 8 & 3.0
\end{tabular}




\begin{tabular}{|c|c|c|c|}
\hline \multirow[t]{2}{*}{ Status } & Menikah & 75 & 30.0 \\
\hline & Belum menikah & 175 & 70.0 \\
\hline \multirow[t]{6}{*}{ Pendidikan terakhir } & $<$ SMA & 0 & 0.0 \\
\hline & SMA \& sederajat & 8 & 3.0 \\
\hline & Diploma (D3/D4) & 2 & 1.0 \\
\hline & $\mathrm{S} 1$ dan sederjat & 219 & 88.0 \\
\hline & S2 dan sederajat & 20 & 8.0 \\
\hline & S3 dan sederajat & 1 & 0.4 \\
\hline \multirow[t]{5}{*}{ Pekerjaan } & Pelajar/Mahasiswa & 72 & 29.0 \\
\hline & Karyawan & 143 & 57.0 \\
\hline & Wiraswasta & 24 & 10.0 \\
\hline & Ibu Rumah Tangga & 5 & 2.0 \\
\hline & Lainnya & 6 & 2.0 \\
\hline \multirow{7}{*}{$\begin{array}{l}\text { Pengeluaran rutin perbulan (di } \\
\text { luar cicilan rumah \& mobil) }\end{array}$} & $\leq 2.000 .000$ & 43 & 17.0 \\
\hline & $2.000 .001-4.000 .000$ & 93 & 37.0 \\
\hline & $4.000 .001-6.000 .000$ & 51 & 20.0 \\
\hline & $6.000 .001-8.000 .000$ & 20 & 8.0 \\
\hline & $8.000 .001-10.000 .000$ & 16 & 7.0 \\
\hline & $>10.000 .000$ & 26 & 10.0 \\
\hline & Tidak bersedia menjawab & 1 & 1.0 \\
\hline \multirow{5}{*}{$\begin{array}{l}\text { Pengeluaran perbulan khusus } \\
\text { konsumsi furnitur/perabot } \\
\text { rumah tangga }\end{array}$} & $\leq 1.000 .000$ & 175 & 70.0 \\
\hline & $1.000 .001-3.000 .000$ & 59 & 24.0 \\
\hline & $3.000 .001-5.000 .000$ & 9 & 4.0 \\
\hline & $>5.000 .000$ & 6 & 2.0 \\
\hline & Tidak bersedia menjawab & 1 & 0.4 \\
\hline \multirow{4}{*}{$\begin{array}{l}\text { Tujuan utama berbelanja di } \\
\text { Ikea Alam Sutera }\end{array}$} & Membeli furnitur/perabot rumah tangga & 88 & 35.0 \\
\hline & Mencari inspirasi desain & 88 & 35.0 \\
\hline & Jalan-jalan & 69 & 28.0 \\
\hline & Lainnya & 5 & 2.0 \\
\hline \multirow{4}{*}{$\begin{array}{l}\text { Durasi berbelanja di Ikea } \\
\text { Alam Sutera }\end{array}$} & $\leq 1 \mathrm{jam}$ & 14 & 6.0 \\
\hline & $>1-2$ jam & 119 & 47.0 \\
\hline & $>2-3 \mathrm{jam}$ & 88 & 35.0 \\
\hline & $>3$ jam & 29 & 12.0 \\
\hline \multirow[t]{2}{*}{$\begin{array}{l}\text { Pernah membeli di Ikea Alam } \\
\text { Sutera }\end{array}$} & Sudah pernah & 201 & 80.0 \\
\hline & Belum pernah & 49 & 20.0 \\
\hline
\end{tabular}

Sumber: Data primer diolah, 2020

Teknik CFA (Confirmatory Factor Analysis) digunakan untuk menguji hipotesis pada hubungan di antara variabel teramati dan konstruk latennya. Melalui model CFA, akan diukur kesuaian terhadap data yang digunakan dan hasil akhir yang diperoleh melalui uji 
kecocokan model, uji validitas dan uji reliabilitas. Pengukuran model CFA dilakukan pada sembilan variabel penelitian yang ditunjukan melalui gambar output dari model pengukuran, tabel output hasil perhitungan CR dan AVE serta $t$-value pada masing-masing variabel. Dari hasil uji reliabilitas melalui perhitungan CR dan AVE terdapat 2 dimensi yaitu store layout and organization dan signage/graphic yang menunjukan nilai AVE $<0,5$ sehingga harus dilakukan respesifikasi model, yang menghasilkan model pengukuran sebagi berikut:

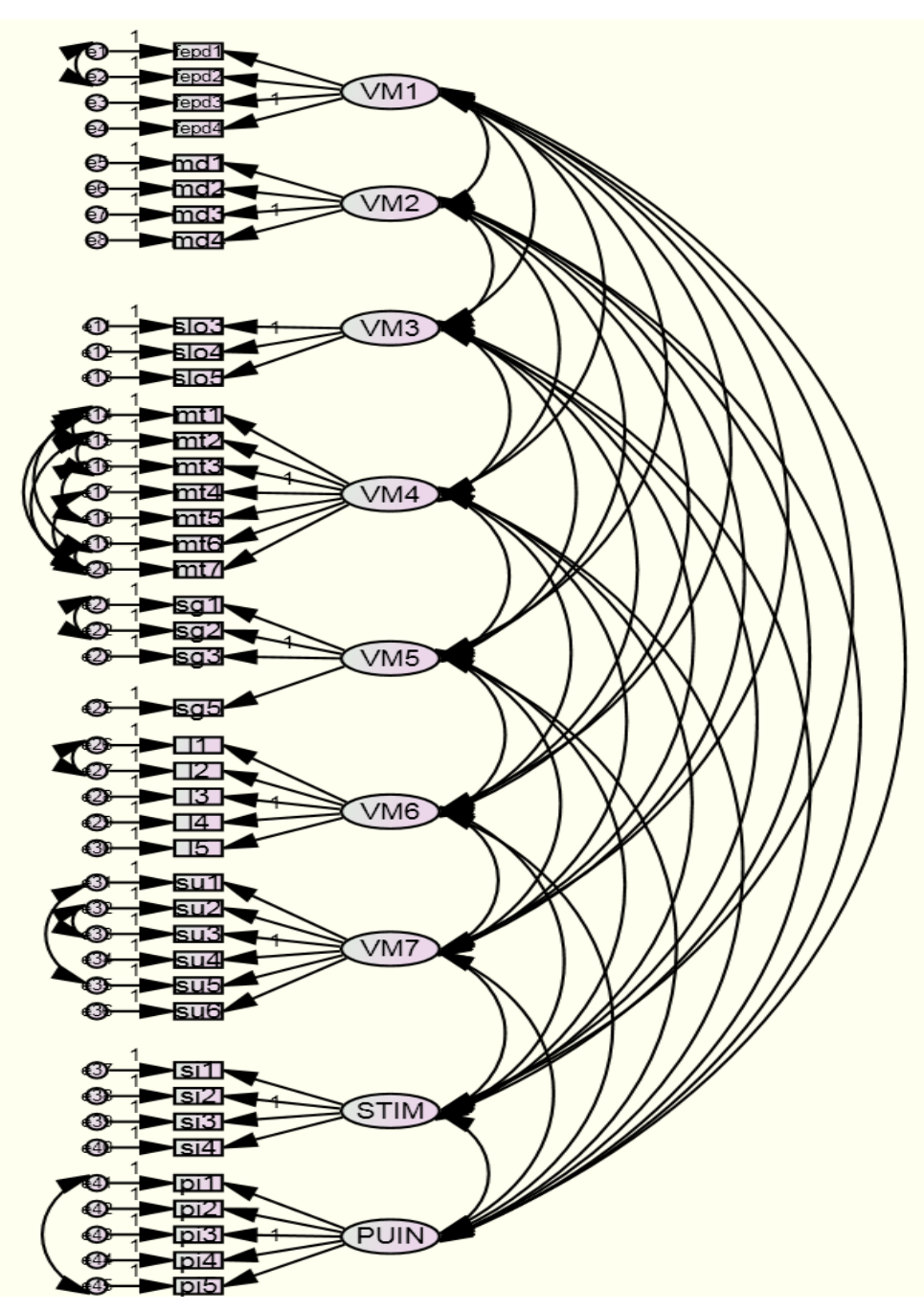

Gambar 2. Respesifikasi Measurment Model

Dari hasil respesifikasi model kemudian diperoleh nilai CR dan AVE yang baik, sebagai berikut: 
Tabel 2. Kesimpulan CR dan AVE per laten

\begin{tabular}{c|c|c|c}
\hline Laten & CR & AVE & Kesimpulan \\
\hline Front entrance product display & 0.8517 & 0.5940 & Baik \\
\hline Merchandising display & 0.8259 & 0.5457 & Baik \\
\hline Store layout \& organization & 0.7668 & 0.5231 & Baik \\
\hline Merchandising theme & 0.9196 & 0.6208 & Baik \\
\hline Signage/graphic & 0.7921 & 0.49 & Baik \\
\hline Lighting & 0.9436 & 0.7702 & Baik \\
\hline Sound usage & 0.8972 & 0.5979 & Baik \\
\hline Store image & 0.8893 & 0.6708 & Baik \\
\hline Purchase intention & 0.8901 & 0.6386 & Baik
\end{tabular}

Sumber: Data primer diolah, 2020

Model pengukuran juga menunjukan nilai Goodness of Fit yang baik, sebagaimana terlihat pada Tabel 2 di bawah ini:

Tabel 3. Goodness of Fit Measurement Model

\begin{tabular}{|c|c|c|c|}
\hline Ukuran GoF & Target Kecocokan & Output Model & Keterangan \\
\hline RMSEA & $\mathrm{RMSEA} \leq 0,08$ & 0,049 & Close Fit \\
\hline GFI & $0,80 \leq \mathrm{GFI} \leq 0,90$ & 0,816 & Marginal Fit \\
\hline NFI & $\mathrm{NFI} \geq 0,90$ & 0,781 & Marginal Fit \\
\hline RFI & $\mathrm{RFI} \geq 0,90$ & 0,760 & Marginal Fit \\
\hline IFI & $\mathrm{IFI} \geq 0,90$ & 0,907 & Good Fit \\
\hline TLI & $\mathrm{TFI} \geq 0,90$ & 0,894 & Marginal Fit \\
\hline CFI & $\mathrm{CFI} \geq 0,90$ & 0,905 & Good Fit \\
\hline RMR & $\mathrm{RMR} \leq 0,05$ & 0,038 & Good Fit \\
\hline
\end{tabular}

Sumber: Data primer diolah, 2020

Model pengukuran secara keseluruhan dapat diterima karena menunjukan tingkat kecocokan (Goodness of Fit) yang baik. Nilai RMSEA bahkan menunjukan close fit yaitu $0,049 \leq 0,08$ walaupun nilai GFI pada area marginal fit yaitu 0,816 atau diantara 0,8 dan 0,9 . Pada pengukuran Incremental Fit, menunjukan hasil yang baik dimana nilai IFI dan CFI menunjukan hasil di atas 0,90 artinya good fit walaupun nilai NFI, RFI dan TLI berada pada area marginal fit.

Sementara itu, pada pengukuran struktural model dilakukan satu kali modifikasi dengan menghubungkan kovariat antara error. Hasil model struktural sebagai berikut: 


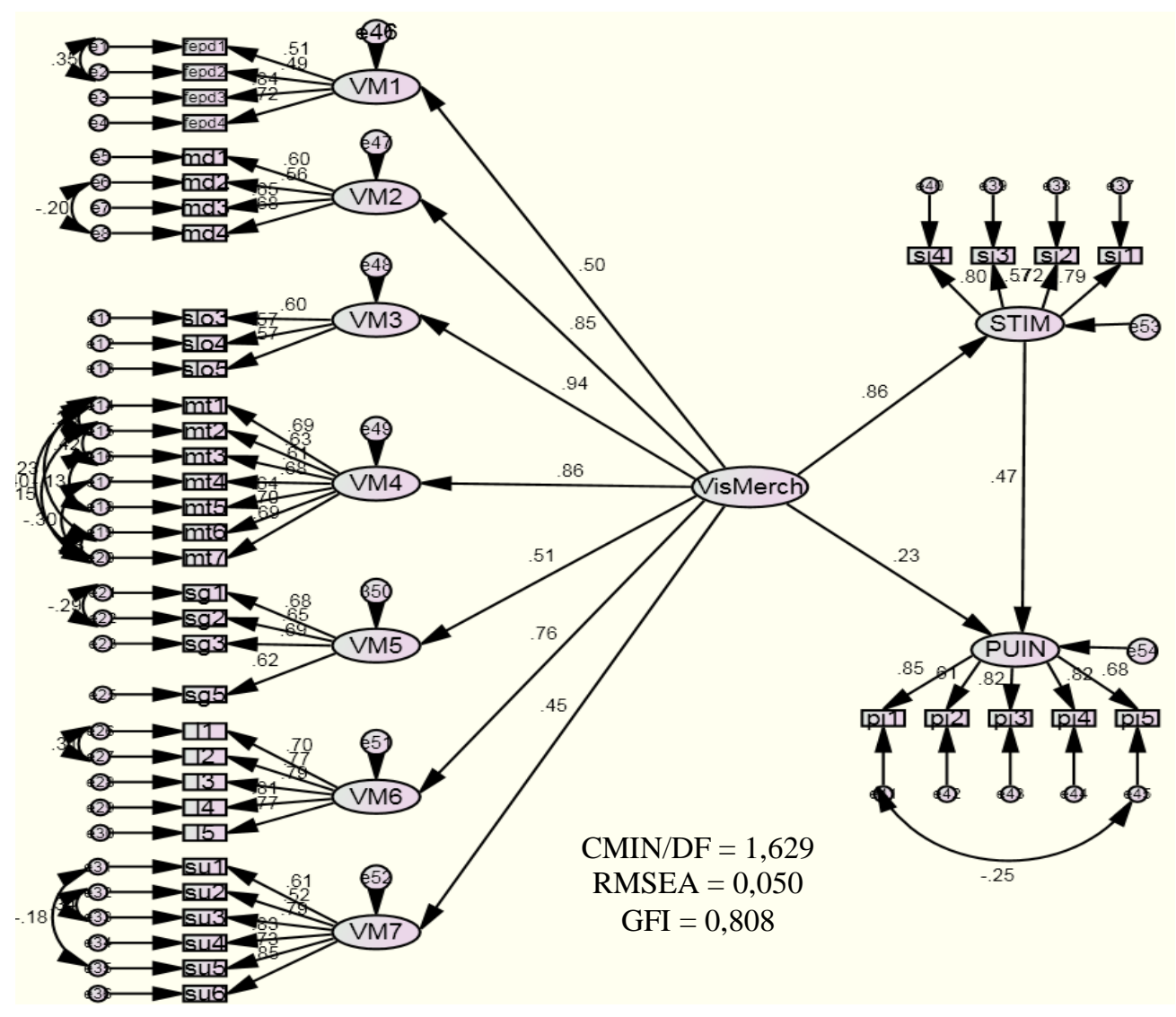

Gambar 3. Model Struktural

Gambar 2 adalah hasil estimasi persamaan model struktural yang ditunjukan melalui hubungan pengaruh satu variabel terhadap variabel lainnya. Tahap selanjutnya yaitu uji kecocokan model (Goodness of Fit). Secara keseluruhan hasil uji Goodness of Fit memenuhi kriteria dan menunjukan kecocokan yang baik (Tabel 4).

Tabel 4. Uji Goodness of Fit Structural Model

\begin{tabular}{|c|c|c|c|}
\hline Ukuran GoF & Target Kecocokan & Hasil Output Model & Keterangan \\
\hline GFI & $\leq 0,90$ & 0,808 & Marginal Fit \\
\hline AGFI & $\leq 0,90$ & 0,781 & Marginal Fit \\
\hline RMR & $\mathrm{RMR} \leq 0,05$ & 0,041 & Good Fit \\
\hline RMSEA & $\mathrm{RMSEA} \leq 0,08$ & 0,05 & Close Fit \\
\hline NFI & $\mathrm{NFI} \geq \overline{0,90}$ & 0,775 & Marginal Fit \\
\hline RFI & $\mathrm{RFI} \geq 0,90$ & 0,757 & Marginal Fit \\
\hline IFI & IFI $\geq 0,90$ & 0,899 & Marginal Fit \\
\hline TLI & $\mathrm{TFI} \geq 0,90$ & 0,889 & Marginal Fit \\
\hline CFI & $\mathrm{CFI} \geq 0,90$ & 0,898 & Marginal Fit \\
\hline
\end{tabular}

Sumber: Data primer diolah, 2020

Setelah structural model dianggap memiliki kecocokan yang baik atau fit, maka dilakukan analisis hubungan antar variabel satu dan lainnya. 
Tabel 5. Hasil Output Regression Weights H1, H2 dan H3

\begin{tabular}{ll|rcccc}
\hline & & Estimate & S.E. & C.R. & P & Label \\
\hline STIM <--- & VisMerch & 1.013 & .141 & 7.165 & $* * *$ & par_54 \\
PUIN <--- & VisMerch & .366 & .247 & 1.484 & .138 & par_55 \\
PUIN <--- & STIM & .628 & .219 & 2.869 & .004 & par_56 \\
\hline
\end{tabular}

Sumber: Data primer diolah, 2020

Pada output model struktural, kolom estimate menunjukan kovarians antara variabel laten dan indikatornya. Kolom $\mathrm{P}$ atau probability sebagian besar menunjukan nilai *** artinya mendekati $0(<0,001)$. Kolom C.R. (Critical Ratio) menunjukan nilai $t$-value. Hubungan antara variabel visual merchandising (VisMerch) terhadap varibel store image (STIM) menunjukan nilai C.R lebih dari 1,96 yaitu 7,165 dan nilai $p$-value *** atau $<0,001$, artinya terdapat pengaruh positif dari variabel VisMerch terhadap STIM. Begitupula dengan hubungan antara variabel STIM terhadap varibel purchase intention (PUIN) menunjukan nilai C.R 2,869 (> 1,96) dan nilai p-value 0,004 atau kurang dari 0,05. Artinya pada tingkat signifikansi 5\% terdapat pengaruh positif dari variabel STIM terhadap PUIN.

Namun hubungan variabel VisMerch ke variabel PUIN menghasilkan nilai C.R 1,484 atau kurang dari nilai $t$-value yang diharapkan yaitu 1,96 dan nilai P sebesar 0,138 atau lebih dari 0,05. Dengan demikian tidak ada hubungan yang signifikan di antara kedua konstruk tersebut. Oleh karena itu dapat disimpulkan bahwa: (1) Variabel visual merchandising memiliki pengaruh positif terhadap variabel store image;(2) Variabel visual merchandising tidak memiliki pengaruh terhadap variabel purchase intention;(3) Variabel store image memiliki pengaruh positif terhadap variabel purchase intention;

Selanjutnya tahap uji kecocokan model struktural dilakukan untuk menganalisa pengaruh dari dimensi-dimensi pembentuk variabel visual merchandising terhadap variabel store image dan variabel purchase intention. Oleh karena itu, dibuat model struktural baru, seperti Gambar 3. 


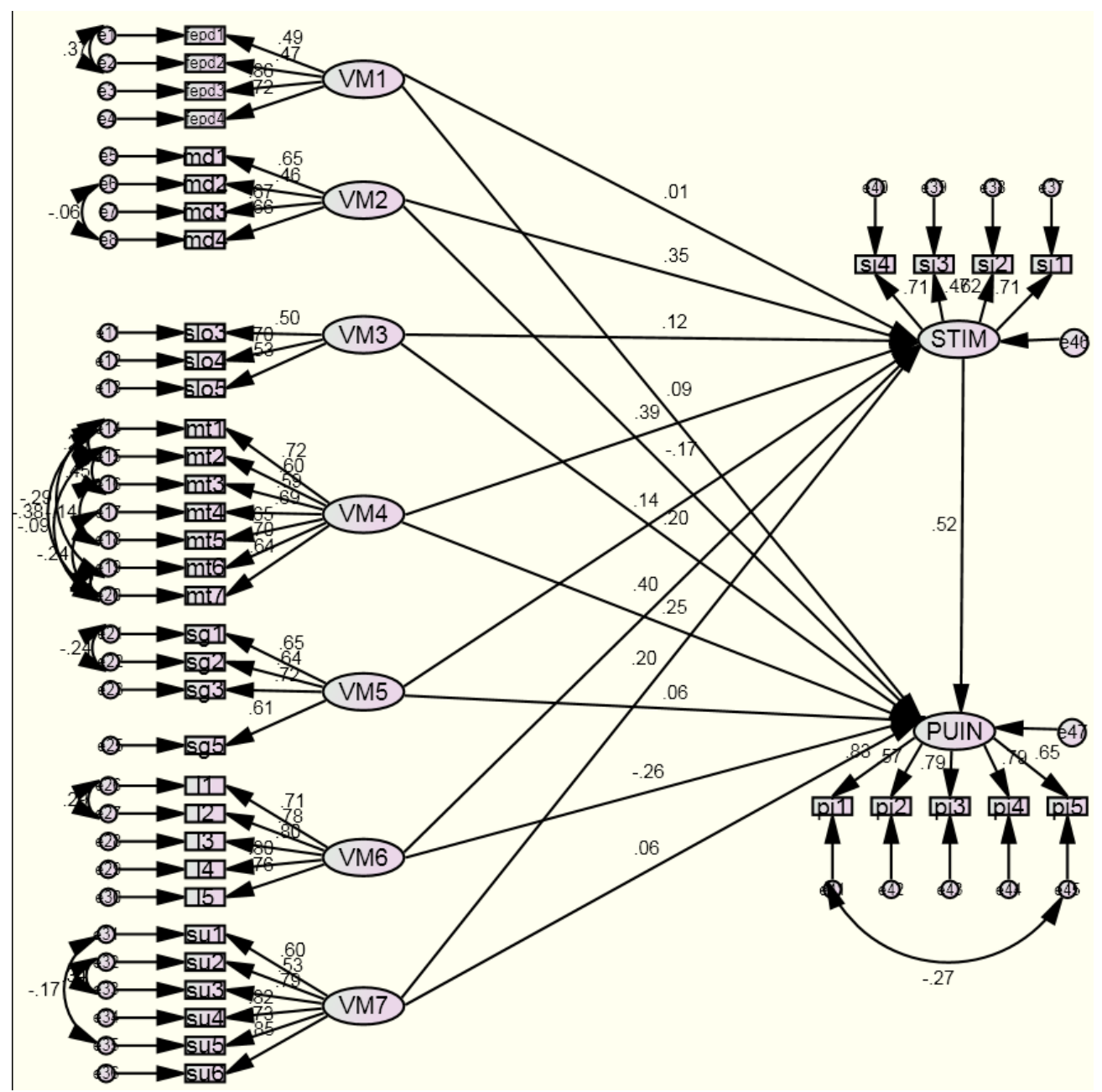

Gambar 4. Hasil Hipotesis Penelitian (Hipotesis Turunan)

Dari model struktural ini diperoleh hasil output regression weights sebagai berikut:

Tabel 5. Evaluasi Model Struktural dan Kesesuaiannya dengan Hipotesis

\begin{tabular}{c|c|c|c|c}
\hline Hipotesis & Path & $\mathbf{C . R}$. & $\mathbf{p}$-value & Kesimpulan \\
\hline $\mathbf{1}$ & $\begin{array}{c}\text { Visual merchandising memiliki pengaruh } \\
\text { positif terhadap store image }\end{array}$ & $\mathbf{7 , 1 6 5}$ & $<\mathbf{0 , 0 0 1}$ & $\begin{array}{c}\text { Data mendukung } \\
\text { hipotesis }\end{array}$ \\
\hline $1 \mathrm{a}$ & $\begin{array}{c}\text { Front entrance product display memiliki } \\
\text { pengaruh terhadap store image. }\end{array}$ & 0,151 & 0,880 & $\begin{array}{c}\text { Data tidak mendukung } \\
\text { hipotesis }\end{array}$ \\
\hline $1 \mathrm{~b}$ & $\begin{array}{c}\text { Merchandising display memiliki pengaruh } \\
\text { positif terhadap store image. }\end{array}$ & 3,890 & $<0,001$ & $\begin{array}{c}\text { Data mendukung } \\
\text { hipotesis }\end{array}$ \\
\hline $1 \mathrm{c}$ & $\begin{array}{c}\text { Store layout \& organization tidak memiliki } \\
\text { pengaruh terhadap store image. }\end{array}$ & 1,517 & 0,129 & $\begin{array}{c}\text { Data tidak mendukung } \\
\text { hipotesis }\end{array}$ \\
\hline $1 \mathrm{~d}$ & $\begin{array}{c}\text { Merchandising theme memiliki pengaruh } \\
\text { positif terhadap store image. }\end{array}$ & 4,503 & $<0,001$ & $\begin{array}{c}\text { Data mendukung } \\
\text { hipotesis }\end{array}$ \\
\hline $1 \mathrm{e}$ & $\begin{array}{c}\text { Signage/graphic memiliki pengaruh positif } \\
\text { terhadap store image. }\end{array}$ & 1,912 & 0,050 & $\begin{array}{c}\text { Data mendukung } \\
\text { hipotesis }\end{array}$ \\
\hline
\end{tabular}




\begin{tabular}{c|c|c|c|c}
\hline $1 \mathrm{f}$ & $\begin{array}{c}\text { Lighting memiliki pengaruh positif terhadap } \\
\text { store image. }\end{array}$ & 4,960 & $<0,001$ & $\begin{array}{c}\text { Data mendukung } \\
\text { hipotesis }\end{array}$ \\
\hline $1 \mathrm{~g}$ & $\begin{array}{c}\text { Sound usage memiliki pengaruh positif } \\
\text { terhadap store image. }\end{array}$ & 2,892 & 0,004 & $\begin{array}{c}\text { Data mendukung } \\
\text { hipotesis }\end{array}$ \\
\hline $\mathbf{2}$ & $\begin{array}{c}\text { Visual merchandising tidak memiliki } \\
\text { pengaruh terhadap purchase intention. }\end{array}$ & $\mathbf{1 , 4 8 4}$ & $\mathbf{0 , 1 3 8}$ & $\begin{array}{c}\text { Data tidak mendukung } \\
\text { hipotesis }\end{array}$ \\
\hline $2 \mathrm{a}$ & $\begin{array}{c}\text { Front entrance product display tidak } \\
\text { memiliki pengaruh terhadap purchase } \\
\text { intention. }\end{array}$ & 1,387 & 0,165 & $\begin{array}{c}\text { Data tidak mendukung } \\
\text { hipotesis }\end{array}$ \\
\hline $2 \mathrm{~b}$ & $\begin{array}{c}\text { Merchandising display tidak memiliki } \\
\text { pengaruh terhadap purchase intention. }\end{array}$ & $-2,039$ & 0,041 & $\begin{array}{c}\text { Data tidak mendukung } \\
\text { hipotesis }\end{array}$ \\
\hline $2 \mathrm{c}$ & $\begin{array}{c}\text { Store layout \& } \text { organization memiliki } \\
\text { pengaruh positif terhadap purchase } \\
\text { intention. }\end{array}$ & 2,531 & 0,011 & $\begin{array}{c}\text { Data mendukung } \\
\text { hipotesis }\end{array}$ \\
\hline $2 \mathrm{~d}$ & $\begin{array}{c}\text { Merchandising theme memiliki pengaruh } \\
\text { positif terhadap store image. }\end{array}$ & 3,139 & 0,002 & $\begin{array}{c}\text { Data mendukung } \\
\text { hipotesis }\end{array}$ \\
\hline $2 \mathrm{e}$ & $\begin{array}{c}\text { Signage/graphic tidak memiliki pengaruh } \\
\text { terhadap purchase intention. }\end{array}$ & 0,848 & 0,396 & $\begin{array}{c}\text { Data tidak mendukung } \\
\text { hipotesis }\end{array}$ \\
\hline $2 \mathrm{f}$ & $\begin{array}{c}\text { Lighting tidak memiliki pengaruh terhadap } \\
\text { purchase intention. }\end{array}$ & $-3,253$ & 0,001 & $\begin{array}{c}\text { Data tidak mendukung } \\
\text { hipotesis }\end{array}$ \\
\hline $2 \mathrm{~g}$ & $\begin{array}{c}\text { Sound usage tidak memiliki pengaruh } \\
\text { terhadap store image. }\end{array}$ & 0,879 & 0,379 & $\begin{array}{c}\text { Data tidak mendukung } \\
\text { hipotesis }\end{array}$ \\
\hline $\mathbf{3}$ & $\begin{array}{c}\text { Store image } \text { memiliki pengaruh positif } \\
\text { terhadap purchase intention. }\end{array}$ & $\mathbf{3 , 8 2 1}$ & $<\mathbf{0 , 0 0 1}$ & $\begin{array}{c}\text { Data mendukung } \\
\text { hipotesis }\end{array}$ \\
\hline $\mathrm{Su}$
\end{tabular}

Sumber: Data primer diolah, 2020

Hasil evaluasi model struktural menunjukan bahwa terdapat pengaruh positif dari dimensi merchandising display (VM2), merchandising theme (VM4), signage/graphic (VM5), lighting (VM6) dan sound usage (VM7) terhadap store image (STIM). Dibuktikan dengan nilai C.R $>1,645$ dan $p$-value $<\alpha(0,05)$. Namun dua dimensi visual merchandising yaitu front entrance product display (VM1) dan store layout and organization (VM3) menghasilkan nilai C.R <1,645 dan $p$-value sebesar $>\alpha$. Maka kedua dimensi ini tidak terbukti memiliki pengaruh terhadap store image.

Tabel 6. Hasil Output Standardized Regression Weights

\begin{tabular}{lll|r}
\hline & & & Estimate \\
\hline STIM & $<---$ & VisMerch & .862 \\
PUIN & $<---$ & VisMerch & .235 \\
PUIN & $<---$ & STIM & .474 \\
\hline
\end{tabular}

Sumber: Data primer diolah, 2020

Berdasarkan Output Standardized Regression Weights diperoleh hasil bahwa store image (STIM) dipengaruhi secara positif oleh visual merchandising (VisMerch). Nilai estimasi menunjukan 0,862 atau pengaruh yang dihasilkan sebesar 86,2\%. Di sisi lain, hubungan antara visual merchandising (VisMerch) dengan purchase intention (PUIN) memiliki nilai estimasi 0,235 atau pengaruh yang diberikan hanya sebesar $23,5 \%$ dengan nilai C.R. $1.484<1,96$ dan $p$-value $0,138>\alpha(0,05)$. Walaupun terdapat dua dimensi visual merchandinsing yaitu store layout \& organization dan merchansing theme yang 
menunjukan nilai C.R. $>1,96$ dan $p$-value $<\alpha(0,05)$, yang artinya terdapat pengaruh positif dari kedua dimensi VM tersebut terhadap variabel purchase intention, namun 5 dimensi lainnya tidak menunjukan data yang mendukung hipotesis. Sehingga dapat disimpulkan bahwa variabel visual merchandising tidak memiliki pengaruh terhadap variabel purchase intention. Sementara itu purchase intention (PUIN) terbukti dipengaruhi secara positif oleh store image (STIM). Nilai estimate 0,474 artinya pengaruh yang dihasilkan sebesar $47,4 \%$, didukung pula dengan nilai C.R 3,821 > 1,645 dan $p$-value $0,001<\alpha(0,05)$.

\section{DISKUSI}

Di dalam penelitian ini, peneliti mengidentifikasi beberapa temuan. Pertama, hasil menunjukan bahwa lima dari tujuh dimensi visual merchandising memiliki pengaruh yang signifikan terhadap variabel store image yaitu merchandising display $\left(\mathrm{H}_{1 \mathrm{~b}}\right)$, merchandising theme $\left(\mathrm{H}_{1 \mathrm{~d}}\right)$, signage/graphic $\left(\mathrm{H}_{1 \mathrm{e}}\right)$, lighting $\left(\mathrm{H}_{1 \mathrm{f}}\right)$ dan sound usage $\left(\mathrm{H}_{1 \mathrm{~g}}\right)$. Sementara dua dimensi lain yaitu front entrance product display $\left(\mathrm{H}_{1 \mathrm{a}}\right)$ dan store layout \& organization $\left(\mathrm{H}_{1 \mathrm{c}}\right)$ tidak menunjukan pengaruh yang signifikan terhadap store image. Sehingga hipotesis 1 dapat disetujui bahwa visual merchandising memiliki pengaruh positif terhadap store image.

Dimensi merchandising display secara positif mampu mempengaruhi citra toko, artinya penataan produk di Ikea Alam Sutera yang tersusun rapi dapat memvisualisasikan bagaimana penataan produk/dekorasi rumah yang memberikan suasana lingkungan berbelanja yang menyenangkan bagi pelanggan. Merchandising theme merupakan dimensi kedua yang paling mempengaruhi citra toko. Pelanggan merasa tampilan produk di Ikea Alam Sutera memberikan inspirasi tentang bagaimana menghias rumah mereka sendiri dan Ikea Alam Sutera juga menampilkan gaya terbaru dari perabot rumah tangga. Semakin menarik tema yang ditampilkan oleh Ikea maka akan tercipta mood pelanggan yang baik dan membuat pelanggan semakin memiliki citra positif terhadap Ikea.

Kemudian signage/graphic yang berupa papan petunjuk yang terlihat jelas dan diletakkan secara baik membuat pelanggan tidak memerlukan bantuan salesperson. Ini juga menjadi indikator yang mempengaruhi persepsi pelanggan bahwa gerai Ikea Alam Sutera memberi kemudahan. Dimensi lighting atau pencahayaan yang digunakan di Ikea Alam Sutera membuat produk terlihat jelas dan menarik bagi pelanggan. Hasil penelitian ini membuktikan teori yang dipaparkan oleh (Madhavi dan Leelavati, 2013) yaitu toko yang terang dengan pencahayaan yang semakin baik mampu mempengaruhi kenyamanan yang lebih tinggi bagi para pelanggan. Dan terakhir, keberadaan background music mampu meningkatkan kesenangan dan kenyamanan pengunjung. Hal ini yang membuat pelanggan memiliki citra positif bahwa Ikea menawarkan lingkungan berbelanja yang menyenagkan dan nyaman.

Temuan kedua, hipotesis 2 tidak dapat diterima sebab hasil analisis data menunjukan bahwa dimensi variabel visual merchandising tidak menunjukan pengaruh positif terhadap variabel purchase intention. Walaupun dimensi store layout and organization $\left(\mathrm{H}_{2 \mathrm{c}}\right)$ dan merchandising theme $\left(\mathrm{H}_{2 \mathrm{~d}}\right)$ menunjukan memiliki pengaruh yang signifikan tetapi sebagian besar dimensi VM lain yaitu front entrance product display $\left(\mathrm{H}_{2 \mathrm{a}}\right)$, merchandising display $\left(\mathrm{H}_{2 \mathrm{~b}}\right)$, signage/graphic $\left(\mathrm{H}_{2 \mathrm{e}}\right)$, lighting $\left(\mathrm{H}_{2 \mathrm{f}}\right)$ dan sound usage $\left(\mathrm{H}_{2 \mathrm{~g}}\right)$, tidak menunjukan pengaruh yang signifikan terhadap minat beli konsumen. Hasil ini sesuai dengan penelitian 
yang dilakukan oleh (Seock dan Lee, 2013) yang menyatakan bahwa tidak ada dimensi dari visual merchandising yang memiliki hubungan dengan jumlah pembelian saat berbelanja di toko favorit pelanggan. Bahkan label harga tidak memiliki hubungan yang signifikan dengan perilaku berbelanja di ritel perabot rumah tangga. Penelitian tersebut menemukan bahwa pelanggan lebih sensitif terhadap ide/tren berbelanja.

Temuan ketiga, sesuai dengan hipotesis 3 yaitu store image berpengaruh positif terhadap purchase intention. Penelitian membuktikan bahwa ketika terbentuk persepsi toko yang nyaman dan menyenangkan pada diri responden ketika berbelanja, maka responden akan memiliki keinginan untuk mengunjungi dan berbelanja kembali di Ikea Alam Sutera. Bahkan responden berkeinginan untuk memberitahu mengenai kesan baik mereka terhadap Ikea tersebut kepada orang lain. Responden juga merasa bahwa lingkungan berbelanja yang nyaman akan membuat mereka berbelanja lebih lama di Ikea Alam Sutera.

\section{KESIMPULAN}

Berdasarkan hasil analisis dan pembahasan yang telah dilakukan dalam penelitian ini, dapat ditarik kesimpulan bahwa elemen-elemen visual merchandising (VM) di Ikea Alam Sutera yang dirancang untuk menciptakan suatu pengalaman berbelanja yang mengesankan, memiliki pengaruh positif dan menjadi sinyal penting dalam mengkomunikasikan citra gerai Ikea. Dalam penelitian ini, VM dibentuk oleh tujuh dimensi yaitu front entrance product display, merchandising display, store layout \& organization, merchandising theme, signage/graphic, lighting dan sound usage. Dari ketujuh dimensi VM terdapat dua dimensi yang tidak mempengaruhi citra toko dan lima dimensi VM lainnya memiliki pengaruh yang positif terhadap citra toko. Oleh karena itu disimpulkan bahwa visual merchandising memiliki pengaruh positif terhadap store image.

Visual merchandising tidak memiliki pengaruh terhadap purchase intention. Hal ini dikarenakan sebagian besar pengunjung yang datang ke Ikea Alam Sutera memiliki tujuan hanya untuk mencari inspirasi desain atau sekedar jalan-jalan saja. Penelitian membuktikan bahwa VM yang telah dirancang sedemikian rupa tidak dapat mempengaruhi niat beli pelanggan jika memang pelanggan tidak memiliki tujuan untuk melakukan pembelian. Niat membeli sebuah produk seperti furnitur tentu membutuhkan perencanaan sebelumnya, karena pelanggan harus memikirkan apakah produk memang dibutuhkan dan terdapat tempat untuk meletakkannya di rumah.

Store image memiliki pengaruh positif terhadap purchase intention. Semakin positif persepsi dan image toko yang terbentuk maka pelanggan akan memiliki keinginan untuk mengunjungi, berbelanja kembali di gerai Ikea Alam Sutera dan niat beli pelanggan semakin meningkat. Lingkungan berbelanja yang menyenangkan dan nyaman juga membuat pelanggan berbelanja lebih lama di gerai Ikea. Bahkan pelanggan berkeinginan untuk memberitahu mengenai toko kepada keluarga dan teman-temannya.

Saran. Penelitian ini memiliki beberapa keterbatasan sehingga memiliki kemungkinan mempengaruhi penelitian secara keseluruhan. Pertama, penelitian selanjutnya dapat menggunakan dimensi dari varibel visual merchandising yang berbeda dari penelitian ini. Dimensi yang digunakan dapat disesuaikan dengan aplikasi pada kondisi dari objek toko atau ritel yang ingin diteliti. Kedua, metode penelitian yang digunakan dalam penelitian ini 
bersifat kuantitatif. Untuk penelitian selanjutnya disarankan menggunakan metode kualitatif melalui wawancara/focus group discussion atau gabungan antara metode kuantitatif dan kualitatif untuk mendapatkan pemahaman yang lebih mendalam dari responden.

Dari sisi implikasi bagi pihak manajemen Ikea adalah elemen visual merchandising yaitu merchandising display, merchandising theme dan lighting merupakan elemen yang terbukti efektif berkontribusi menciptakan citra positif bagi Ikea Alam Sutera. Maka dari itu Ikea perlu mempertahankan apa yang telah diterapkan di tiga elemen tersebut. Namun pelanggan saat ini mudah bosan dan sangat sensitif memilih tempat berbelanja yang cocok/sesuai dengan keinginan mereka. Apalagi lokasi Ikea yang berada di Alam Sutera, Tangerang dirasakan cukup jauh untuk dikunjungi khususnya bagi pelanggan yang tidak berdomisili di Tangerang dan membutuhkan effort tersendiri untuk mengunjungi gerai ini. Oleh karena itu ketujuh elemen visual merchandising perlu diperbaharui dalam jangka waktu tertentu. Hal ini untuk mencegah terjadinya kebosanan pelanggan ketika mengunjungi Ikea dan untuk mempertahankan image positif yang telah terbentuk sebelumnya. Perubahan dapat dilakukan menyesuaikan dengan keluaran produk terbaru, tren/lifestyle yang sedang diminati, atau dapat diubah pengaturan desainnya saja agar tampak baru. Selain itu perubahan dapat dilakukan menyesuaikan dengan local culture di Indonesia seperti perayaan hari besar mengingat intensitas pengunjung untuk berbelanja cukup tinggi pada hari-hari menjelang perayaan tersebut.

\section{DAFTAR PUSTAKA}

Banat, A., and Wandebori, H. S. T. (2012). Store Design and Store Atmosphere Effect on Customer Sales per Visit Economics, Management and Behavioral Sciences.

Bell, J., and Ternus, K. (2012). Silent Selling 4rd Edition. New York: Fairchild Publications. Borges et. al. (2013). Gender Orientation and Retail Atmosphere: Effects on Value Perception. International Journal of Retail \& Distribution Management, July 2013

Gudonaviciene, R., and Alijosiene, S. (2015). Visual Merchandising Impact on Impulse Buying Behavior. Procedia - Social and Behavioral Sciences 213: 635-640.

Gupta, V. (2013). Study on Visual Merchandising for Home Furniture Retail Store. International Journal of Retailing \& Rural Business Perspective. vol. 2, no. 3, pp. 555565.

Holbrook, M. B., and Anand, P. (1990). Effects of tempo and situational arousal on the listeners.

Hosseini, Z., Jayashree, S., and Malarvizhi, C. (2014). Store Image and Its Effect on Customer Perception of Retail Stores. Asian Social Science, Vol. 10, No. 21.

Hussain, R., and Ali, M. (2015). Effect of Store Atmosphere on Consumer Purchase Intention. International Journal of Marketing Studies . Vol. 7, No. 2, pp. 35-43.

Kouchekian, M., and Gharibpoor, M. (2012). Investigation the Relationship between Visual Merchandising and Customer Buying Decision Case Study: Isfahan Hypermarkets. International Journal of Academic Research in Economics and Management Sciences, Vol. 1, No. 2, pp. 268-279.

Kleinova, K., et. al. (2015). Visual Merchandising and Its Marketing Components in the Chosen Restaurants in Slovakia. Procedia Economics and Finance 34: 3-10. 
Kpossa, M. R., and Lick, E. (2020). Visual Merchandising of Pastries in Foodscapes: The Influence of Plate Colours on Consumers' Flavour Expectations and Perceptions. Journal of Retailing and Consumer Services, Elsevier, Vol. 52@.

Krishnakumar, M. (2014). The Role of Visual Merchandising in Apparel Purchase Decision. The IUP Journal of Management Research, Vol. XIII, No. 1, 37-54.

Madhavi, S., and Leelavati, T. S. (2013). Impact of Visual Merchandising On Consumer Behavior Towards Women Apparel. International Journal of Management Research and Business Strategy, Vol. 2, No. 4, 61-72.

Malholtra, N.K. (2010). Marketing Research (6th ed). New Jersey: Prentice Hall.

Marketing Essentials. (2012). Glencoe McGraw-Hill Online Education, McGraw-Hill Publisher.

McDaniel et. al. (2012). Marketing Essentials. Sydney: South Western Cengage Learning.

Mehta, N. and Chugan, Pawan K. (2013). The Impact of Visual Merchandising on Impulse Buying Behavior of Consumer: A Case from Central Mall of Ahmedabad India. Universal Journal of Management 1(2): 76-82.

Mehta, N. and Chugan, P. K. (2014). Impact of Visual Merchandising on Consumer Behavior: A Study of Furniture Outlets. Universal Journal of Management 2(6): 207217.

Park, H. H., et al. (2015). How does Visual Merchandising in Fashion Retail Store affect Consumers' Brand Attitude and Purchase Intention. The International Review of Retail, Distribution and Consumer Research, Vol. 25, No. 1, 87-104.

Pecotic, M., Bazdin, V., Samardžija, J. (2014). Interior Design in Restaurants as a Factor Influencing Customer Satisfaction. In: RIThink, Vol. 4, pp. 10 - 14.

Putra, I. R. (2020). Nilai Pasar Mebel Dalam Negeri Diprediksi Tembus Rp 15 Triliun di 2020. https://www.merdeka.com/

Rajendhiran, N., and Manimozhian, K. (2015). Visual Merchandising Impose On In-StoreSales. International Recognized Double-Blind Peer Reviewed Multidisciplinary Research Journal, Vol. 4, Issue $8,1-5$.

Seock, Y. K., and Lee, Y. E. 2013. Understanding the Importance of Visual Merchandising on Store Image and Shopper Behaviours in Home Furnishing Retail Setting. European Journal of Business and Management . vol. 5, no. 4, pp. 174-187.

Smith, P., and Ross, C. (1966). Arousal hypothesis and the effect of music on Purchasing Behaviour. Journal of Applied Psychology, 50 , 255-256.

Sugiyono. (2008). Metode Penelitian Kuantitatif Kualitatif dan R\&D. Bandung: ALFABETA.

Turley, L. W., and R. E. Milliman. (2000). Atmospheric Effects on Shopping Behavior: A Review of the Experimental Evidence. Journal of Business Research 49 (2): 193-211.

Watanabe, et. al. (2019). The Impact of Culture, Evaluation of Store Image and Satisfaction on Purchase Intention at Supermarkets. Revista de Gestão Vol. 26 No. 3, 2019 pp. 256-273.

Zolkifly, N. H., and Baharom, S. N. (2016). Selling Cars through Visual Merchandising: Proposing Emotional Design Approach. Procesia Economics and Finance 37: 412417. 